\title{
The Integrated Fuzzy AHP and Goal Programing Model Based on LCA Results for Industrial Waste Management by Using the Nearest Weighted Approximation of FN: Aluminum Industry in Arak, Iran
}

\author{
Ramin Zare, ${ }^{1}$ Jafar Nouri, ${ }^{1}$ Mohammad Ali Abdoli, ${ }^{2}$ Farideh Atabi, ${ }^{3}$ and Majid Alavi ${ }^{4}$ \\ ${ }^{1}$ Department of Environmental Management, Graduate School of Environment and Energy, Islamic Azad University, \\ Science and Research Branch, Tehran 1477893855, Iran \\ ${ }^{2}$ Faculty of Environment, University of Tehran, P.O. Box 14155-6135, Tehran 3836119131, Iran \\ ${ }^{3}$ Department of Environmental Engineering, Graduate School of Environment and Energy, Islamic Azad University, \\ Science and Research Branch, Tehran 1477893855, Iran \\ ${ }^{4}$ Department of Mathematics, Islamic Azad University, Arak Branch, Arak, Iran
}

Correspondence should be addressed to Jafar Nouri; nourijafar@gmail.com

Received 16 July 2015; Accepted 16 November 2015

Academic Editor: Steve Bull

Copyright (C) 2016 Ramin Zare et al. This is an open access article distributed under the Creative Commons Attribution License, which permits unrestricted use, distribution, and reproduction in any medium, provided the original work is properly cited.

\begin{abstract}
The worldwide recycled aluminum generation is increasing quickly thanks to the environmental considerations and continuous growing of use demands. Aluminum dross recycling, as the secondary aluminum process, has been always considered as a problematic issue in the world. The aim of this work is to propose a methodical and easy procedure for the proposed system selection as the MCDM problem. Here, an evaluation method, integrated FAHP, is presented to evaluate aluminum waste management systems. Therefore, we drive weights of each pair comparison matrix by the use of the goal programming (GP) model. The functional unit includes aluminum dross and aluminum scrap, which is defined as 1000 kilograms. The model is confirmed in the case of aluminum waste management in Arak. For the proposed integrated fuzzy AHP model, five alternatives are investigated. The results showed that, according to the selected attributes, the best waste management alternative is the one involving the primary aluminum ingot $99.5 \%$ including $200 \mathrm{~kg}$ and the secondary aluminum $98 \%$ (scrap) including $800 \mathrm{~kg}$, and beneficiation activities are implemented, duplicate aluminum dross is recycled in the plant, and finally it is landfilled.
\end{abstract}

\section{Introduction}

Nowadays, aluminum is used in industry, transportation, and construction and packaging industries, more increasingly. In aluminum industries, the secondary aluminum production grows rapidly due to the issues pertaining to the environmental considerations and the rise in the consumption demands. It is estimated that the production of this material will reach $2.60 \times 10^{7} \mathrm{t}$ in 2015 [1]. In the following, FAHP methodology has been considered to evaluate the environmental, economical, and social impacts of the aluminum waste. To ameliorate the MCDM procedure and facilitate aluminum waste system choice process, the present research will use a fuzzy integrated approach to represent decision-makers' judgments, which is utilized to evaluate the weight of criteria and alternatives. Then, literature, the results of questionnaires, overviews, and the results of the primary life cycle assessment are evaluated by experts by the use of fuzzy linguistic terms.

This approach allowed us to numerically display vagueness and to reflect the decision-makers' perception of the decision-making process as well.

This research is comprised of the following sections.

In Section 2, we give some related literature concerning the proposed problem a once-over. In Section 3, as methodology, we review some basic concepts, and finally the proposed algorithm is explained. In Section 4, a case study related to the aluminum waste is presented. The study ends with a discussion and conclusion. 


\section{Literature Review}

Total primary aluminum consumption in the world was of $50.2 \mathrm{Mt}$ in 2013 [2]. The manufacture of aluminum from alumina demands much more energy than other metals and leads to major quantities of greenhouse gas pollutants [3]. Aluminum production is responsible for $1.1 \%$ of the annual greenhouse gas emissions [4]. It is about $75 \%$ of all the aluminum production as secondary aluminum (aluminum scrap and dross) since 1880s which is still in generative use. The findings of these studies indicated that the emissions and energy consumption of aluminum were decreased in the production of secondary aluminum compared to the production of primary aluminum [5]. Authors represented that the aluminum waste recycling is economically and environmentally friendly [6]. Opportunities for recovery and recycle of metals from wastes are high. Recovery of secondary resources such as $\mathrm{Al}, \mathrm{Fe}, \mathrm{Cu}$, and $\mathrm{Zn}$ from these wastes is gaining increasing interest [7, 8]. Also, by recycling secondary aluminum, resources are saved, the need for landfill area could have been decreased, and the public opinion would be satisfied. A lot of dross is produced as a waste product during remelting or refining aluminum [9]. Although aluminum dross is a waste of current resources, in case of being landfilled without suitable treatment, it will lead to the secondary contaminants which would affect air, water, and soil [1]. Aluminum wastes, mainly, are disposed of in landfill sites, which may result in leaking of toxic metal ions into the ground water. Also, when aluminum waste comes in contact with water it emits poisonous gases as $\mathrm{NH}_{3}, \mathrm{CH}_{4}, \mathrm{PH}_{3}, \mathrm{H}_{2}$, and $\mathrm{H}_{2} \mathrm{~S}[10,11]$. The environmental effects of aluminum scrap from recycled aluminum should be minimized. That is why, in this study, the effects and impacts of aluminum waste management systems are evaluated. In addition, aluminum dross recycling has been always considered as a problematic issue. The fuzzy set idea was used by [12] to manage uncertainty in the inventory data. Seppälä modified and compared the fuzzy approach presented in [13] to the "traditional" valuation method of LCA [14]. Since Van Laarhoven, Pedrycz, and Buckley [15, 16] offered their initial study in FAHP, numerous works have applied FAHP in disparate environment problems [1720]. Also, some studies applied FAHP method concerning LCA thinking. For example, this methodology was applied by Zheng et al. in the building sector [21] and by Chan and Lin to evaluate green product design $[19,22]$. Complex decision-making situations are relevant to the aluminum waste management system which needs the realization of different sections of the industry and community. However, little attention has been given to the environmental aspects of the processing output of aluminum dross and aluminum scrap as aluminum waste in MCDM methodologies.

\section{Methodology}

The aim of this work is to offer a methodical and straightforward and simple to use method for the aluminum waste management system selection problem. MCDM methods were considered for this aim, including fuzzy logic, fuzzy comparison matrix, NWIA, the GP method, and the fuzzy AHP.

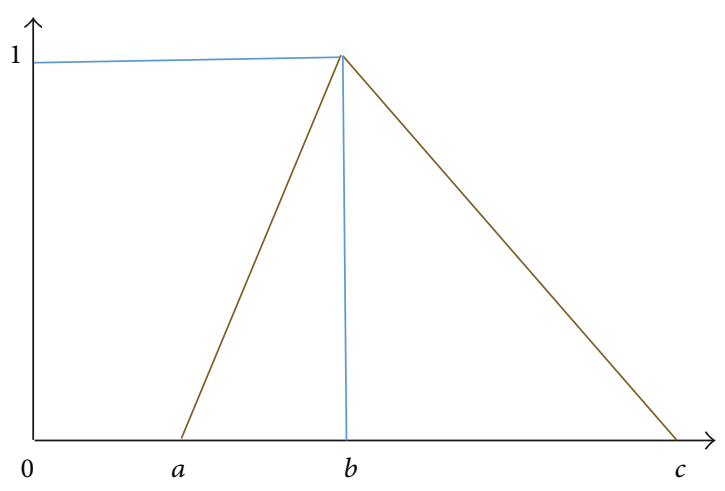

Figure 1: Typical triangular fuzzy number.

3.1. Fuzzy Numbers (FN). FN are one path to explain the ambiguity and be missing accuracy of data [23]. A fuzzy number is a fuzzy set $A: R \rightarrow I=[0,1] R$ that satisfied the following:

(1) “ $A$ " is continuous.

(2) $A(x)=0$ outside some interval $[a, c]$.

(3) There are real numbers $a, b$, and $c$ so that $a \leq b \leq c$.

And

(a) $A(x)=1, x=b$,

(b) $A(x)$ is decreasing on $[b, c]$,

(c) $A(x)$ is increasing on $a \leq x \leq b$.

The set of all such fuzzy numbers is represented by $F(\mathbb{R})$. Fuzzy number with linear sides and the membership function having the following form (see Figure 1)

$$
A(X)= \begin{cases}\frac{x-a}{b-a}, & a \leq x \leq b, \\ \frac{c-x}{c-b}, & b \leq x \leq c \\ 0, & \text { otherwise }\end{cases}
$$

is called triangular fuzzy number and is denoted by $\widetilde{A}=$ $(a ; b ; c)$.

3.2. Fuzzy Pair Comparison Matrix. Consider the expert that prepares fuzzy opinion in place of exact opinion. It presumes trade to be with comparison matrix with triangular FN being the components of the matrix. We suppose a matrix whose components are $\mathrm{FN}$ as

$$
\widetilde{A}=\left(\begin{array}{ccc}
\left(a_{11}^{L}, a_{11}^{M}, a_{11}^{U}\right) & \cdots & \left(a_{1 n}^{L}, a_{1 n}^{M}, a_{1 n}^{U}\right) \\
\vdots & \ddots & \vdots \\
\left(a_{n 1}^{L}, a_{n 1}^{M}, a_{n n}^{U}\right) & \cdots & \left(a_{n n}^{L}, a_{n n}^{M}, a_{n n}^{U}\right)
\end{array}\right)
$$


where $\tilde{a}=\left(\alpha_{i j}^{L}, \alpha_{i j}^{M}, \alpha_{i j}^{U}\right)$ is a triangular FN; see [24]. It is supposed that $\widetilde{A}$ is reciprocal, if the following term is satisfied [25]:

$$
\begin{gathered}
\widetilde{\alpha}_{i j}=\left(\alpha_{i j}^{L}, \alpha_{i j}^{M}, \alpha_{i j}^{U}\right), \quad \forall i, j=1, \ldots, n \\
\text { implies that } \widetilde{\alpha}_{i j}=\left(\frac{1}{\alpha_{i j}^{U^{\prime}}}, \frac{1}{\alpha_{i j}^{M^{\prime}}}, \frac{1}{\alpha_{i j}^{L^{\prime}}}\right), \\
\forall i, j=1, \ldots, n .
\end{gathered}
$$

3.3. The Nearest Weighted Interval Approximations (NWIAs). In this section, we review an interval processor of $\mathrm{FN}$, which is denoted by NWIA. We apply a fuzzy weighted spacing quantity on the FN. Then, we acquire the interval approximations for $\mathrm{FN}$ [26].

$\widetilde{A}$ function is as $f=(\underline{f}, \bar{f}):([0,1],[0,1]) \rightarrow(\mathbb{R}, \mathbb{R})$ and functions $f, \bar{f}$ are not negative, are uniformly increasing, and satiate the undernormalization term:

$$
\int_{0}^{1} \underline{f}(a) d a=\int_{0}^{1} \bar{f}(a) d a=1 .
$$

Now, let $\widetilde{A}$ be a fuzzy number with $A_{\alpha}=[a(\alpha), \bar{a}(\alpha)]$ and let $f(\alpha)=(\underline{f}(\alpha), \bar{f}(\alpha))$ be a weighted function. Then the interval

$$
\operatorname{NWIA}_{f}(A)=\left[\int_{0}^{1} \underline{f}(a) \underline{a}(a) d a, \int_{0}^{1} \bar{f}(a) \bar{a}(a) d a\right]
$$

is NWIA to FN $\widetilde{A}$.

In usage, the function $f(\alpha)$ may be selected pursuant to the real term.

If $\widetilde{A}=(a, b, c)$, which is a triangular $\mathrm{FN}$, and $f(\alpha)=$ $\left(n \alpha^{n-1}, n \alpha^{n-1}\right)$, which is a weighting function, so

$$
\operatorname{NWIA}_{f}(A)=\left[\frac{a+n b}{n+1}, \frac{n b+c}{n+1}\right] .
$$

Example 1. In this example $\widetilde{A}=(3,4,7)$ is a triangular FN; also, $f_{1}(\alpha)=(2 \alpha, 2 \alpha)$ and $f_{2}(\alpha)=\left(4 \alpha^{3}, 4 \alpha^{3}\right)$ are two weighting functions. Then, the nearest weighted interval to $\widetilde{A}$ is as follows (Figure 2) [26]:

$$
\begin{aligned}
\operatorname{NWIA}_{f 1}(A) & =\left[\frac{11}{3}, 5\right], \\
\operatorname{NWIA}_{f 2}(A) & =\left[\frac{19}{5}, \frac{23}{5}\right] .
\end{aligned}
$$

3.4. Goal Programming (GP). The GP attempts to combine optimal logic and the preference of decision-maker in arithmetical programming in order to satiate several goals. The decision-making environment determines basic concepts including goal and system restrictions and aim function variables. This means that GP presents the way for concurrent goal attainment [27].

Weighted GP is a capable tool since it includes several factors simultaneously in the decision-making process and,

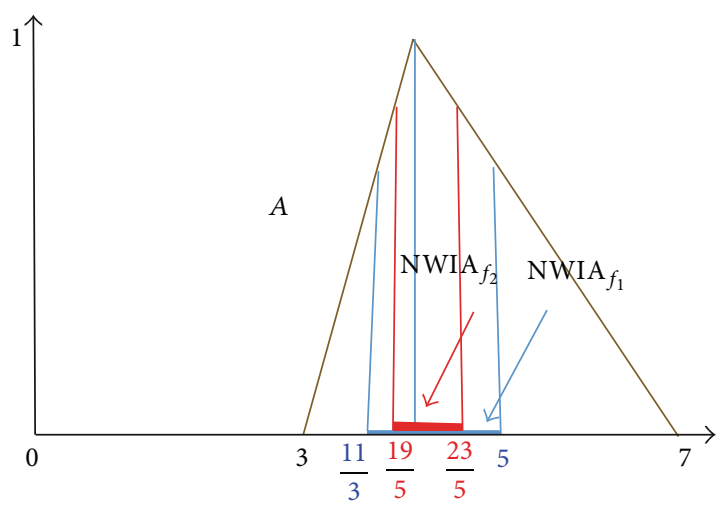

FIGURE 2: Triangular FN and its interval approximation.

at the same time, regards the system's restriction. Of course using nonquantitative and intangible factors or criteria is out of the capability of this planning model. Therefore mix AHP and a supplementary tool capable of solving the shortcomings of weighted goal planning can shape a suitable model for organization decision-making such as optimizing the result mixture.

Regard the following problem:

$$
\begin{aligned}
\operatorname{Max} & \left\{f_{1}(x), \ldots, f_{k}(x)\right\} \\
\text { s.t. } & x \in X,
\end{aligned}
$$

where $f_{1}, \ldots, f_{k}$ are goal functions and $X$ is not empty in an achievable region. Model (4) is now a significant area of MCDM mathematical programming. The conception of goal programming is to set up an aim level of gaining each indicator. This procedure needs the decision-maker to consider a goal for each aim that someone wishes to obtain. A favored result is then explained as the one which reduces the deflections from set objectives to the smallest possible amount. After that, the GP may be presented as

$$
\begin{array}{ll}
\min & \sum_{i=1}^{k}\left(d_{i}^{+}+d_{i}^{-}\right) \\
\text {s.t. } & f_{i}(x)+d_{i}^{+}-d_{i}^{-}=b_{i}, \quad i=1, \ldots, k, \\
& x \in X \\
& d_{i}^{+} d_{i}^{-}=0, \quad i=1, \ldots, k, \\
& d_{i}^{+}, d_{i}^{-} \geq 0, \quad i=1, \ldots, k .
\end{array}
$$

The decision-makers in their objectives set some acceptive dream levels for these objectives and attempt to obtain a collection of objectives as intimately as feasible. The aim of programming is to reduce the perversions between the attainment of objectives, $f_{i}(x)$, and these acceptive dream levels, $b_{i}(i=1, \ldots, k)$. In addition, $d_{i}^{+}$and $d_{i}^{-}$are up and down attainment of the $I$ th objective, respectively.

3.5. Deriving the Weights of Criteria. In the routine situation, whenever a matrix $A$ is reciprocal and consistent, afterwards the weights of criteria are computed as 


$$
W_{i}=\frac{a_{i j}}{\sum_{k=1}^{n} a_{k j}}, \quad i=1, \ldots, n .
$$

In the situation of inconsistence matrix, we should achieve the significance weights or equally $\alpha_{i j} w_{j}-w_{i}=0$. Hence in the situation of ambiguity, for deriving the weights from inconsistence fuzzy matrix we do as [26].

Step 1. First by (8) we convert each fuzzy component $\widetilde{\alpha}_{i j}=$ $\left(\alpha_{i j}^{L}, \alpha_{i j}^{M}, \alpha_{i j}^{U}\right)$ of the comparison matrix to NWIA $\bar{\alpha}_{i j}=$ $\left[\alpha_{i j}^{-L}, \alpha_{i j}^{-U}\right]$. Therefore, the fuzzy comparison matrix $\widetilde{A}$ is transformed to an interval matrix $\bar{A}$.

Therefore we present deviation variables $p_{i j}^{-}, p_{i j}^{+}$and $q_{i j}^{-}$, $q_{i j}^{+}$, which lead to

$$
\begin{aligned}
& a_{i j}^{-L} w_{i}-w_{i}+p_{i j}^{-}-p_{i j}^{+}=0, \\
& w_{i}-a_{i j}^{-U} w_{i}+p_{i j}^{-}-p_{i j}^{+}=0,
\end{aligned}
$$

where deviation variables $p_{i j}^{-}, p_{i j}^{+}$and $q_{i j}^{-}, q_{i j}^{+}$are not negative real numbers but may not be positive concurrently, which is, $p_{i j}^{-} p_{i j}^{+}=0$ and $q_{i j}^{-} q_{i j}^{+}=0$. Now we use the GP procedure. It is worthwhile that the deviation variables $p_{i j}^{-}$and $p_{i j}^{+}$remain to be as little as possible, which drive to the following GP model [26]:

$$
\begin{array}{ll}
\min & \sum_{i=1}^{n} \sum_{j=1}^{n}\left(p_{i j}^{-}+p_{i j}^{+}\right), \quad i=1, \ldots, n \\
\text { s.t. } & a_{i j}^{-L} w_{i}-w_{i}+p_{i j}^{-}-p_{i j}^{+}=0, \quad i, j=1, \ldots, n, \\
& w_{i}-a_{i j}^{-U} w_{i}+q_{i j}^{-}-q_{i j}^{+}=0, \quad i, j=1, \ldots, n, \\
& \sum_{i=1}^{n} w_{i}=1, \\
& w_{i}, p_{i j}^{-}, p_{i j}^{+}, q_{i j}^{-}, q_{i j}^{+} \geq 0 .
\end{array}
$$

By the resolvent model (12), we acquire the optimal weight vector $W=\left(w_{1}, \ldots, w_{n}\right)$ and display the significance of each indicator. We can use these weights in the course of solving a multiple criteria decision-making problem. To solve this problem, we apply the linear programming software LINGO11.

Example 2 (matrix with triangular fuzzy number). Regard $3 \times$ 3 reciprocal matrix $\widetilde{A}$ with $\mathrm{FN}$ :

$$
\widetilde{A}=\left(\begin{array}{ccc}
1,1,1 & 2,3,4 & 4,5,6 \\
\frac{1}{4}, \frac{1}{3}, \frac{1}{2} & 1,1,1 & 3,4,5 \\
\frac{1}{6}, \frac{1}{5}, \frac{1}{4} & \frac{1}{5}, \frac{1}{4}, \frac{1}{3} & 1,1,1
\end{array}\right)
$$

We apply the function $f_{1}(\alpha)=(2 \alpha, 2 \alpha)$. Afterwards, by applying equality (7), the interval approximation pairwise comparison matrix is acquired as

$$
\begin{aligned}
& \widetilde{A} \\
& =\left(\begin{array}{lll}
{[1.000,1.000]} & {[2.667,3.333]} & {[4.667,5.333]} \\
{[0.303,0.387]} & {[1.000,1.000]} & {[3.667,4.333]} \\
{[0.192,0.217]} & {[0.233,0.278]} & {[1.000,1.000]}
\end{array}\right) .
\end{aligned}
$$

We build the GP procedure for the mentioned interval approximation matrix as

$$
\begin{aligned}
& \text { Min }=p_{12 l}+p_{12 u}+q_{12 l}+q_{12 u}+p_{13 l}+p_{13 u}+q_{13 l} \\
& \quad+q_{13 u}+p_{21 l}+p_{21 u}+q_{21 l}+q_{21 u}+p_{23 l}+p_{23 u} \\
& \quad+q_{23 l}+q_{23 u}+p_{31 l}+p_{31 u}+q_{31 l}+q_{31 u}+p_{32 l} \\
& \quad+p_{32 u}+q_{32 l}+q_{32 u} ; \\
& 2.365 * w_{2}-w_{1}+p_{12 l}-p_{12 u}=0 \\
& w_{1}-2.958 * w_{2}+q_{12 l}-q_{12 u}=0 \\
& 1.099 * w_{2}-w_{1}+p_{13 l}-p_{13 u}=0 \\
& w_{1}-1.367 * w_{2}+q_{13 l}-q_{13 u}=0 \\
& 0.320 * w_{1}-w_{2}+p_{21 l}-p_{21 u}=0 \\
& w_{2}-0.418 * w_{1}+q_{21 l}-q_{21 u}=0 \\
& 2.713 * w_{3}-w_{2}+p_{23 l}-p_{23 u}=0 \\
& w_{2}-3.512 * w_{3}+q_{23 l}-q_{23 u}=0 \\
& 0.763 * w_{1}-w_{3}+p_{31 l}-p_{31 u}=0 \\
& w_{3}-0.928 * w_{1}+q_{31 l}-q_{31 u}=0 \\
& 0.303 * w_{2}-w_{3}+p_{32 l}-p_{32 u}=0 \\
& w_{3}-0.367 * w_{2}+q_{32 l}-q_{32 u}=0 \\
& w_{1}+w_{2}+w_{3}=1 ; \\
& \quad
\end{aligned}
$$

END

By solving GP (15), we achieve the optimal vector $W=$ $(0.63,0.26,0.09)$. We may apply these weights in the process of solving a MCDM problem. In addition, these weights display that indicator 1 is more significant than others (see Table 1). In this case the grade arrangement of these indicators is as follows:

$$
W_{1}>W_{2}>W_{3}
$$

The results of ranking these criteria are presented in Table 1.

3.6. FAHP Method. The AHP approach applies multicriteria decision analysis developed $b$ presented by Saaty [28], to compute the weighting factor of attribute. The AHP method is constructed on the pairwise comparison to compute the 
TABLE 1: The result of ranking of proposed method.

\begin{tabular}{lcc}
\hline Criterion & Weight & Rank \\
\hline 1 & $W_{1}=0.6334$ & 1 \\
2 & $W_{2}=0.2678$ & 2 \\
3 & $W_{3}=0.0987$ & 3 \\
\hline
\end{tabular}

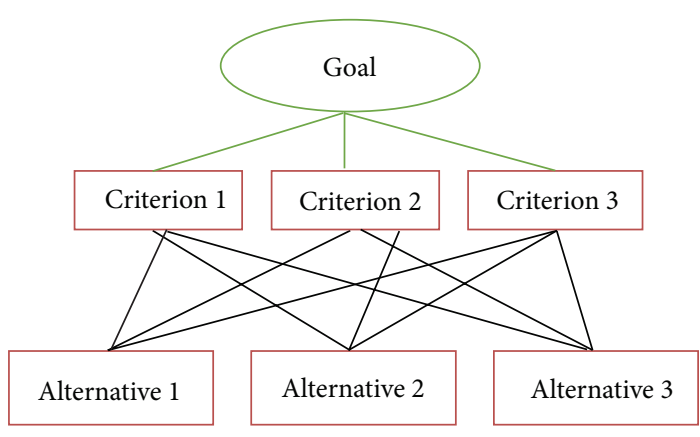

Figure 3: A hierarchical structure.

weight of each criterion. The AHP permits experts to determine the significance of each criterion during comparing other criteria from 1 to 9 , from "same importance" (1) to "completely more important" (9). Building a decision tree, decision-maker is permitted to first describe weights of the main criteria, and then decision-maker can describe the lower level subcriteria that exactly describe the tested multicriteria issue [28].

The AHP method may not handle the ambiguity in determining the rankings of various attributes [29]. Also, it is usually hard to evaluate various factors because of a lack of suitable data. In FAHP method, quid pro quo of allocating definite quantities, the adjudications are built by applying linguistic parameters and are characterized by fuzzy membership functions. The fuzzy geometric mean method is the most accepted method to construct the matrix. The relict procedures are just routine AHP.

3.7. Proposed Algorithm. An algorithm to determine the most preferable aluminum waste management system selection among all possible alternatives, when data is fuzzy, by using GP and the NWIA, with the extended AHP method is given in the following.

Step 1 (set up the expert group). To evaluate alternatives, an expert group comprised of researcher and managers should be formed.

Step 2. Create a hierarchical structure of elements for problem solving. For this propose, it is necessary for decisionmakers to determine criteria and subcriteria based on proposing the main target. See, for example, Figure 3.

Step 3. Build a set of fuzzy comparison matrices for each decision-maker.

Step 4 (aggregate fuzzy comparison matrices). We aggregate fuzzy comparison matrices constructed by decision-makers by using the geometric mean method and convert them to unit fuzzy comparison matrix,

$$
\text { where } \begin{aligned}
a_{i j}^{L} & =\left(\prod_{k=1}^{5} a_{i j}^{L k}\right)^{1 / 5}, \\
a_{i j}^{M} & =\left(\prod_{k=1}^{5} a_{i j}^{M K}\right)^{1 / 5}, \\
a_{i j}^{U} & =\left(\prod_{k=1}^{5} a_{i j}^{U K}\right)^{1 / 5}, \\
& \left(a_{i j}^{L k}, a_{i j}^{M K}, a_{i j}^{U K}\right), k=1,2, \ldots, 5,
\end{aligned}
$$

is the important opinion of the $K$ th decision-maker.

Step 5 (deriving the weights of each matrix). For this purpose, we apply the following substeps.

Step 5.1. By using (7), we convert each fuzzy matrix to an interval fuzzy matrix.

Step 5.2. By resolving model (12), we can achieve the weight of each comparison matrix.

Step 6 (aggregate the weights and rank the alternatives). We aggregate the weights and rank the alternatives and finally select the best aluminum waste management system. The priority weight of each option may be achieved by multiplying the matrix of assessment by the vector of characteristic weights and adding over all characteristics [30].

\section{Case Study}

A case study on aluminum manufacturers and particularly aluminum remelter plants in Arak, an industrial city in Iran, is introduced. It illustrates how the proposed fuzzy AHP methodology according to the algorithm can be applied to selecting the best aluminum waste management system.

Twenty-nine remelting facilities were incorporated in this research. The secondary aluminum remelting is considered as a unit function. As shown in Figure 4, this process unit includes the storage in place (1), beneficiation activities (2) related to input aluminum scrap such as washing, separating, and sorting (or without beneficiation activities (3)), remelting in the crucible furnace (4), duplicate aluminum black dross recycling in plant (5) (or exporting aluminum black dross to another place and duplicate recycling (6)), and final waste landfilling (7) (or release in the environment (8)).

All the results are based on the reference flow of 1 ton of aluminum batch, including new and old aluminum scraps and white and black aluminum dross (see Figure 5). The upkeep and repair of the plant and equipment materials are provided to this life cycle stage from both primary and secondary aluminum processing. Also, the secondary remelters have a diversity of melting furnaces: top-loaded closed, rotary, and side well-feeding melting. They have 


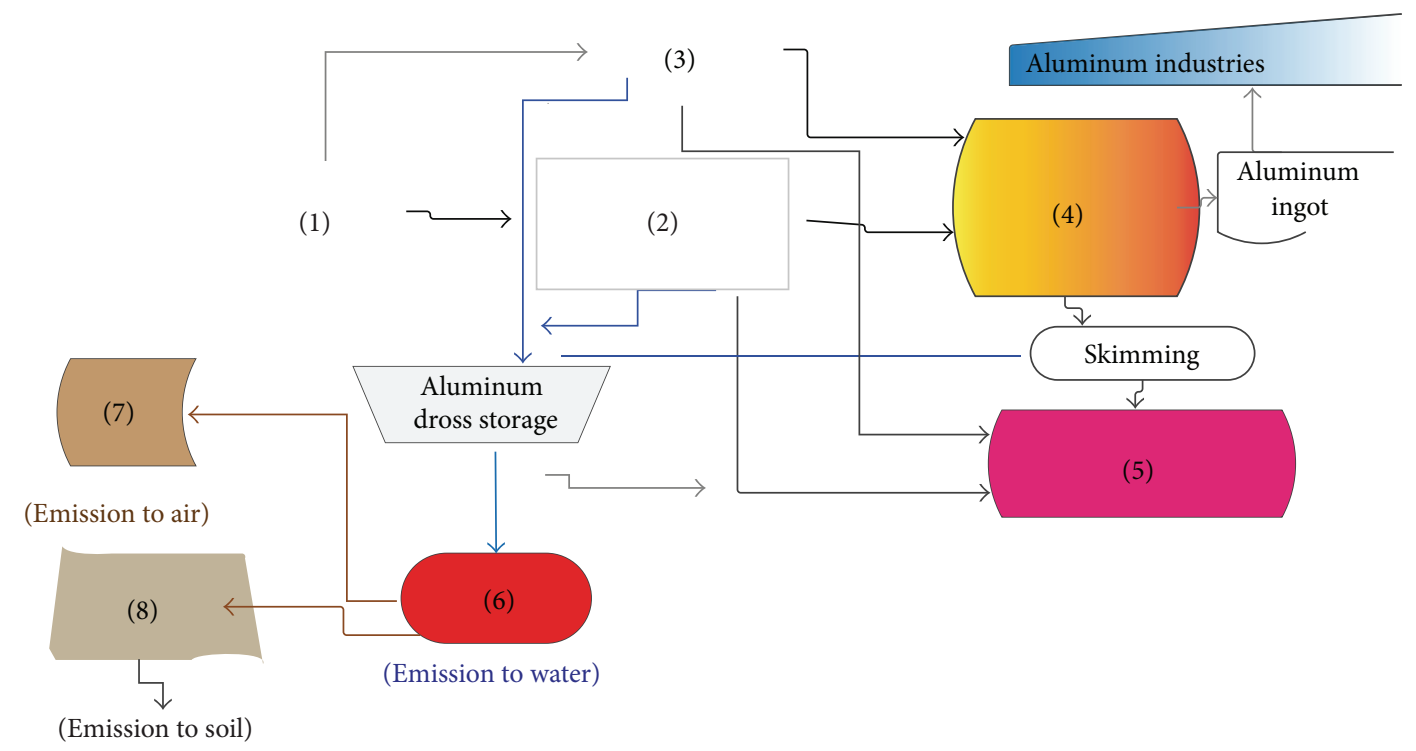

FigURE 4: Flowchart of the secondary aluminum remelting in proposed research.

different competence. In this study, the crucible furnace for the secondary aluminum remelting is used.

In this study, firstly, a panel of experts as the decisionmaker group was set up. The decision-makers were five experts: three engineers from the production managers of aluminum industries and two academics in the environment and management fields. Then, literature, financial documents, statistics of occupational accidents, the results of overviews, and the primary LCA, were evaluated by the decision-makers using fuzzy linguistic terms. This approach allowed us to mathematically represent uncertainty and vagueness and reflect the decision-maker's perception of decision-making process. After this, a questionnaire was distributed to the decision-makers to evaluate and characterize the importance weights of the criteria and ratings of the options.

Once the answers were collected, the questionnaire results were studied and the discussions were directed to confirm the data reliability. Figure 6 shows the decision hierarchy for the decision-making issue. In the upper ranks of the hierarchy we have the general aim which in this instance is the choice of an aluminum waste management system. We presented the main criteria including environmental, social, and economic aspects at level 2. The associated common attributes or subcriteria (level 3) are the main criteria. These general attributes are broken down into global warming (GWP), human toxicity (HTP), land use (LU), health and safety at work (H\&S), regulation (Reg), turnover, and gain. At level 4, we showed five management options.

Five management alternatives for aluminum waste management in Arak are presented as follows:

(i) Alternative "A": aluminum crucible for remelting, aluminum batch, includes the primary aluminum ingot $99.5 \%$ including $200 \mathrm{~kg}$ and the secondary aluminum 96\% (scrap) including $800 \mathrm{~kg}$, beneficiation activities, related to input aluminum scrap such as washing, separating, and sorting, exporting aluminum black dross to another place, duplicate recycling, and landfill.

(ii) Alternative "B": aluminum crucible for remelting, aluminum batch, includes the primary aluminum ingot $99.5 \%$ including $200 \mathrm{~kg}$ and the secondary aluminum with a grade $96 \%$ (scrap) including $800 \mathrm{~kg}$, remelting without beneficiation activities, exporting remaining aluminum black dross to another place and duplicate recycling, and release in the environment.

(iii) Alternative "C": aluminum crucible for remelting, aluminum batch, includes the primary aluminum ingot $99.5 \%$ including $200 \mathrm{~kg}$ and the secondary aluminum 96\% (scrap) including $800 \mathrm{~kg}$, beneficiation activities related to input aluminum black scrap such as washing, separating, and sorting, duplicate aluminum dross recycling in plant, and landfill.

(iv) Alternative $\mathrm{D}$, defined as the present current aluminum waste management system: aluminum crucible for remelting, aluminum batch, includes the primary aluminum ingot $99.5 \%$ including $200 \mathrm{~kg}$ and the secondary aluminum 96\% (scrap) including $800 \mathrm{~kg}$, remelting without beneficiation activities, exporting aluminum black dross to another place and duplicate recycling, and release in the environment.

(v) Alternative E: aluminum crucible for remelting, aluminum batch, includes the primary aluminum ingot $99.5 \%$ including $200 \mathrm{~kg}$ and the secondary aluminum $98 \%$ (scrap) including $800 \mathrm{~kg}$, beneficiation activities related to input aluminum scrap such as washing, separating, and sorting, duplicate aluminum black dross recycling in plant, and landfill.

Alternative " $A$ " is defined as the "intermediate" waste management system. Alternative B is defined as the current 


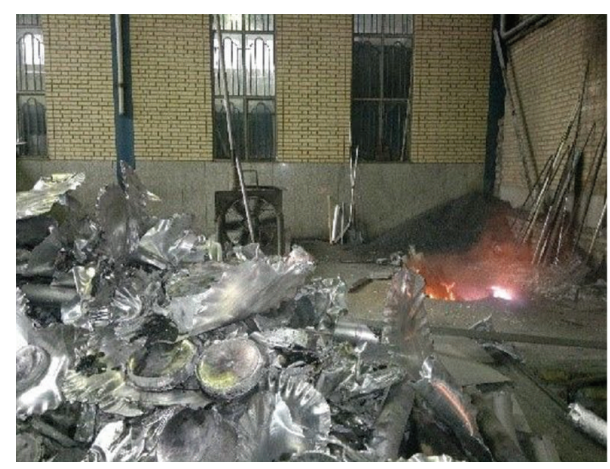

(a) New aluminum scrap

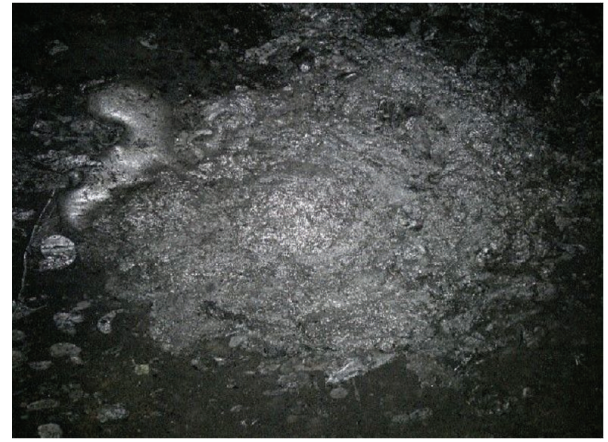

(c) White aluminum dross

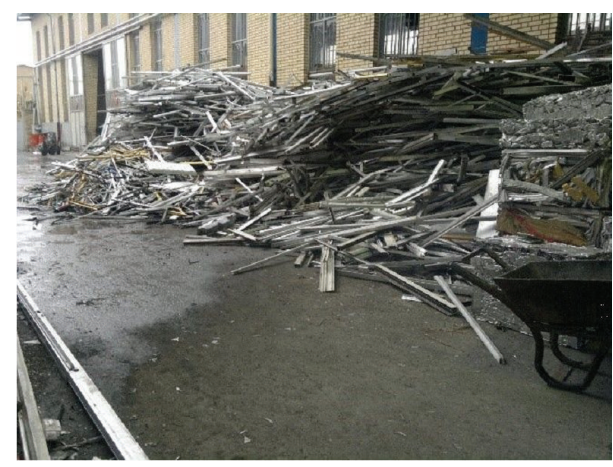

(b) Old aluminum scrap

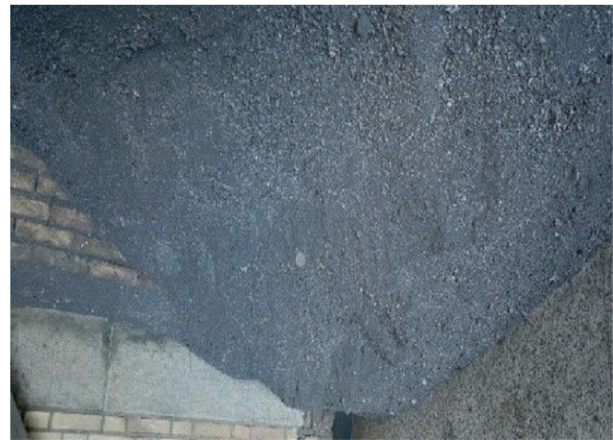

(d) Black aluminum dross

FIGURE 5: Aluminum wastes in the proposed study.

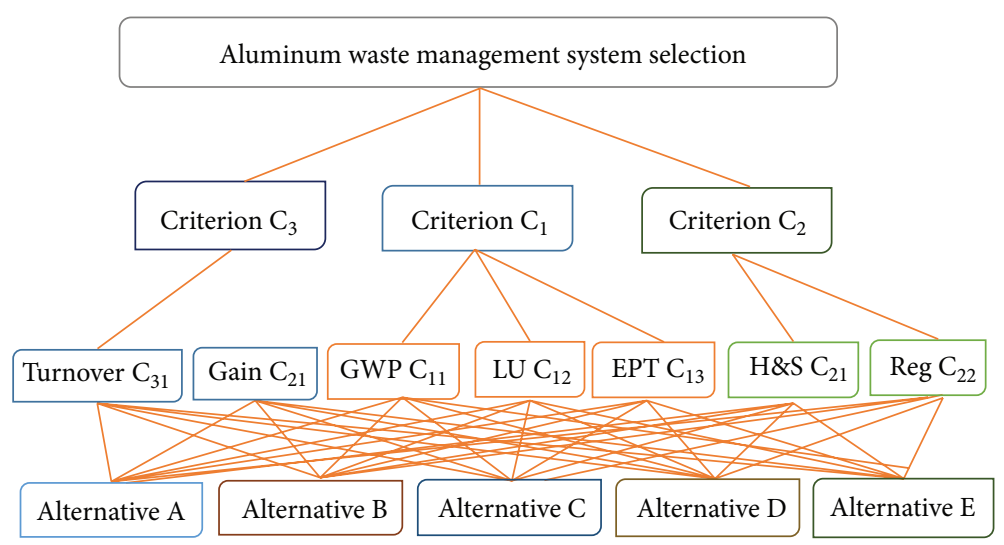

FIgURE 6: The hierarchical structure in the proposed research.

waste management system. It is similar to alternative $\mathrm{A}$, but instead of landfill method, the aluminum waste is released in the environment. Alternative C represents "business" option, where economic benefits are more important. Alternative D represents "waste export" where approximately $70 \%$ of aluminum waste that is normally landfilled is exported to another place to duplicate recycling. Alternative E is defined as the environmentally friendly system.

Pairwise comparison concerning the main target is presented in Table 2.

Pairwise comparison matrix subcriteria concerning the basic criteria are presented in Table 3.

Comparison matrix subcriteria concerning the alternatives are as in Tables 4-10.
TABLE 2: Criteria concerning the main target.

\begin{tabular}{lccc}
\hline Main target & $\mathrm{C}_{1}$ & $\mathrm{C}_{1}$ & $\mathrm{C}_{1}$ \\
\hline $\mathrm{C}_{1}$ & $(1,1,1)$ & $(4.22,6.26,8.28)$ & $(4.72,6.26,8.28)$ \\
$\mathrm{C}_{2}$ & $(0.12,0.16,0.21)$ & $(1,1,1)$ & $(3,5,7)$ \\
$\mathrm{C}_{3}$ & $(0.12,0.16,0.21)$ & $(0.14,0.2,0.33)$ & $(1,1,1)$ \\
\hline
\end{tabular}

The results of interval approximation of pairwise comparison matrices are presented in Tables 11-19.

The calculating of weighted approximation related to Table 12 is presented in Example 2.

As shown in Table 20, alternative " $E$ " is assigned as the most preferable choice, with a weight of 0.594161 ; alternative 
TABLE 3: Subcriteria concerning the main criteria.

(a)

\begin{tabular}{lccr}
\hline Environmental $\left(\mathrm{C}_{1}\right)$ & $\mathrm{C}_{11}$ & $\mathrm{C}_{12}$ & $\mathrm{C}_{13}$ \\
\hline $\mathrm{C}_{11}$ & $(1,1,1)$ & $(1.18,2.76,3.56)$ & $(0.84,1.18,1.91)$ \\
$\mathrm{C}_{12}$ & $(0.19,0.36,0.58)$ & $(1,1,1)$ & $(2.08,2.92,5.28)$ \\
$\mathrm{C}_{13}$ & $(0.52,0.84,1.18)$ & $(0.18,0.34,0.48)$ & $(1,1,1)$ \\
\hline
\end{tabular}

(b)

\begin{tabular}{lcr}
\hline Social $\left(\mathrm{C}_{2}\right)$ & $\mathrm{C}_{21}$ & $\mathrm{C}_{22}$ \\
\hline $\mathrm{C}_{21}$ & $(1,1,1)$ & $(2.08,2.92,3.66)$ \\
$\mathrm{C}_{22}$ & $(0.27,0.34,0.48)$ & $(1,1,1)$ \\
\hline & $(\mathrm{c})$ & $\mathrm{C}_{32}$ \\
\hline Economical $\left(\mathrm{C}_{3}\right)$ & $\mathrm{C}_{31}$ & $(2.08,4.21,6.26)$ \\
\hline $\mathrm{C}_{31}$ & $(1,1,1)$ & $(1,1,1)$ \\
$\mathrm{C}_{32}$ & $(0.16,0.24,0.48)$ & \\
\hline
\end{tabular}

TABLE 4: Purposed options concerning GWP subcriteria.

\begin{tabular}{lcccrc}
\hline (GWP) $\mathrm{C}_{11}$ & $\mathrm{~A}$ & $\mathrm{~B}$ & $\mathrm{C}$ & $\mathrm{D}$ & $\mathrm{E}$ \\
\hline $\mathrm{A}$ & $(1,1,1)$ & $(1.44,3.55,5.6)$ & $(0.34,0.46,0.58)$ & $(1,3,5)$ & $(0.15,0.16,0.19)$ \\
$\mathrm{B}$ & $(0.26,0.30,0.41)$ & $(1,1,1)$ & $(0.11,0.14,0.14)$ & $(0.2,0.33,1)$ & $(0.11,0.14,0.14)$ \\
C & $(1,2.29,5)$ & $(7,7,9)$ & $(1,1,1)$ & $(3,5,7)$ & $(0.16,0.24,0.48)$ \\
D & $(0.2,0.33,1)$ & $(1,3,5)$ & $(0.14,0.2,0.25)$ & $(1,1,1)$ & $(0.11,0.14,0.16)$ \\
E & $(4.22,6.25,8.27)$ & $(7,7,9)$ & $(2.08,4.21,6.26)$ & $(5.6,7,9)$ & $(1,1,1)$ \\
\hline
\end{tabular}

TABLE 5: Options concerning the ETP subcriteria.

\begin{tabular}{lccccc}
\hline (ETP) $\mathrm{C}_{12}$ & $\mathrm{~A}$ & $\mathrm{~B}$ & $\mathrm{C}$ & $\mathrm{D}$ & $\mathrm{E}$ \\
\hline $\mathrm{A}$ & $(1,1,1)$ & $(1,3,5)$ & $(0.21,0.25,0.3)$ & $(1,1,3)$ & $(0.13,0.19,0.30)$ \\
$\mathrm{B}$ & $(0.14,0.24,0.28)$ & $(1,1,1)$ & $(0.11,0.14,0.14)$ & $(0.23,0.48,1)$ & $(0.11,0.14,0.14)$ \\
$\mathrm{C}$ & $(2.08,4.21,6.26)$ & $(7,7,9)$ & $(1,1,1)$ & $(5,7,9)$ & $(0.21,0.23,0.36)$ \\
$\mathrm{D}$ & $(0.33,1,1)$ & $(1,2.08,4.22)$ & $(0.12,0.16,0.24)$ & $(1,1,1)$ & $(0.11,0.14,0.16)$ \\
$\mathrm{E}$ & $(1.91,3.97,6.08)$ & $(6.25,7,9)$ & $(2.08,4.21,6.26)$ & $(6.25,7,9)$ & $(1,1,1)$ \\
\hline
\end{tabular}

TABLE 6: Options concerning LU subcriteria.

\begin{tabular}{lccccc}
\hline (LU) $\mathrm{C}_{13}$ & $\mathrm{~A}$ & $\mathrm{~B}$ & $\mathrm{C}$ & $\mathrm{D}$ & $\mathrm{E}$ \\
\hline $\mathrm{A}$ & $(1,1,1)$ & $(4.22,6.25,8.26)$ & $(0.33,1,1)$ & $(1.44,3.55,5.6)$ & $(0.18,0.28,0.69)$ \\
$\mathrm{B}$ & $(0.13,0.18,0.28)$ & $(1,1,1)$ & $(0.11,0.14,0.14)$ & $(0.33,1,1)$ & $(0.11,0.14,0.14)$ \\
$\mathrm{C}$ & $(1,1,3)$ & $(7,7,9)$ & $(1,1,1)$ & $(3,5,7)$ & $(0.23,0.48,1)$ \\
$\mathrm{D}$ & $(0.18,0.28,0.69)$ & $(1,1,3)$ & $(0.14,0.2,0.33)$ & $(1,1,1)$ & $(0.11,0.14,0.14)$ \\
$\mathrm{E}$ & $(1.44,3.55,5.59)$ & $(7,7,9)$ & $(1,2.08,4.21)$ & $(7,7,9)$ & $(1,1,1)$ \\
\hline
\end{tabular}

TABLE 7: Options concerning H\&S subcriteria.

\begin{tabular}{lccccc}
\hline H\&S $\left(\mathrm{C}_{21}\right)$ & $\mathrm{A}$ & $\mathrm{B}$ & $\mathrm{C}$ & $\mathrm{D}$ & $\mathrm{E}$ \\
\hline $\mathrm{A}$ & $(1,1,1)$ & $(0.24,0.28,0.52)$ & $(0.24,0.28,0.52)$ & $(0.11,0.14,0.14)$ & $(0.11,0.14,0.18)$ \\
$\mathrm{B}$ & $(2.08,4.21,6.26)$ & $(1,1,1)$ & $(0.33,1,1)$ & $(0.14,0.2,0.33)$ & $(0.24,0.48,1)$ \\
$\mathrm{C}$ & $(2.08,4.21,6.26)$ & $(1,1,3)$ & $(1,1,1)$ & $(0.24,0.33,0.58)$ & $(0.33,1,1)$ \\
$\mathrm{D}$ & $(7,7,9)$ & $(3,5,7)$ & $(1,3,5)$ & $(1,1,1)$ & $(11.44,3.55)$ \\
$\mathrm{E}$ & $(6.25,7,9)$ & $(1,2.08,4.2)$ & $(1,3,5)$ & $(0.4,0.7,0.7)$ & $(1,1,1)$ \\
\hline
\end{tabular}


TABLE 8: Options concerning regulation subcriteria.

\begin{tabular}{lccccc}
\hline (Reg) $\mathrm{C}_{22}$ & $\mathrm{~A}$ & $\mathrm{~B}$ & $\mathrm{C}$ & $\mathrm{D}$ & $\mathrm{E}$ \\
\hline $\mathrm{A}$ & $(1,1,1)$ & $(3,5.7)$ & $(0.33,1,1)$ & $(1,3,5)$ & $(0.2,0.33,1)$ \\
$\mathrm{B}$ & $(0.14,0.2,0.33)$ & $(1,1,1)$ & $(0.11,0.14,0.14)$ & $(1,1,1)$ & $(0.11,0.14,0.14)$ \\
$\mathrm{C}$ & $(0.7,1,2)$ & $(7,7,9)$ & $(1,1,1)$ & $(3,5.7)$ & $(1,1,1)$ \\
$\mathrm{D}$ & $(0.2,0.33,1)$ & $(1,1,1)$ & $(0.14,0.2,0.33)$ & $(1,1,1)$ & $(0.11,0.14,0.14)$ \\
$\mathrm{E}$ & $(1,3,5)$ & $(7,7,9)$ & $(1,1,1)$ & $(7,7,9)$ & $(1,1,1)$ \\
\hline
\end{tabular}

TABLE 9: Options concerning turnover subcriteria.

\begin{tabular}{lcccrc}
\hline (Turnover) $\mathrm{C}_{31}$ & $\mathrm{~A}$ & $\mathrm{~B}$ & $\mathrm{C}$ & $\mathrm{D}$ & $\mathrm{E}$ \\
\hline $\mathrm{A}$ & $(1,1,1)$ & $(3.55,5.59,7.61)$ & $(0.33,1,1)$ & $(1,3,5)$ & $(0.13,0.24,0.28)$ \\
$\mathrm{B}$ & $(0.14,0.2,0.33)$ & $(1,1,1)$ & $(0.11,0.14,0.14)$ & $(0.33,1,1)$ & $(0.11,0.14,0.14)$ \\
$\mathrm{C}$ & $(1,1,3)$ & $(7,7,9)$ & $(1,1,1)$ & $(3,5.7)$ & $(1,1,1)$ \\
$\mathrm{D}$ & $(0.2,0.33,1)$ & $(0.69,1,1)$ & $(0.12,0.16,0.24)$ & $(1,1,1)$ & $(0.11,0.14,0.14)$ \\
$\mathrm{E}$ & $(3.55,4.18,7.61)$ & $(7,7,9)$ & $(1,1,1)$ & $(7,7,9)$ & $(1,1,1)$ \\
\hline
\end{tabular}

TABLE 10: Options concerning gain subcriteria.

\begin{tabular}{lccccc}
\hline (Gain) $\mathrm{C}_{32}$ & $\mathrm{~A}$ & $\mathrm{~B}$ & $\mathrm{C}$ & $\mathrm{D}$ & $\mathrm{E}$ \\
\hline $\mathrm{A}$ & $(1,1,1)$ & $(0.58,1.4,2.92)$ & $(0.28,0.69,1)$ & $(1.21,2.02,3.66)$ & $(2.08,4.21,6.25)$ \\
$\mathrm{B}$ & $(0.34,0.69,1.7)$ & $(1,1,1)$ & $(1.09,1.7,2.5)$ & $(1,2.08,4.21)$ & $(6.25,7,9)$ \\
C & $(1,1,3)$ & $(0.39,0.58,0.92)$ & $(1,1,1)$ & $(0.18,0.28,0.69)$ & $(1,1,1)$ \\
D & $(0.27,0.49,0.82)$ & $(0.2,0.33,1)$ & $(1,3,5)$ & $(1,1,1)$ & $(5,7,9)$ \\
E & $(0.13,0.24,0.28)$ & $(0.11,0.14,0.2)$ & $(1,1,1)$ & $(0.13,0.14,0.19)$ & $(1,1,1)$ \\
\hline
\end{tabular}

TABLE 11: The interval approximation main target concerning the gain criteria.

\begin{tabular}{lcccc}
\hline Main target & $\mathrm{C}_{1}$ & $\mathrm{C}_{2}$ & $\mathrm{C}_{3}$ & Obtained weights \\
\hline $\mathrm{C}_{1}$ & {$[1,1]$} & {$[5.7,6.8]$} & {$[5.7,6.8]$} & 0.84507 \\
$\mathrm{C}_{2}$ & {$[0.15,0.18]$} & {$[1,1]$} & {$[4.5,5.5]$} & 0.126761 \\
$\mathrm{C}_{3}$ & {$[0.15,0.18]$} & {$[0.18,0.23]$} & {$[1,1]$} & 0.028169 \\
\hline
\end{tabular}

TABLE 12: The interval approximation subcriteria concerning the main criteria.

(a)

\begin{tabular}{lcccc}
\hline Environment & $\mathrm{C}_{11}$ & $\mathrm{C}_{12}$ & $\mathrm{C}_{13}$ & $\begin{array}{c}\text { Obtained } \\
\text { weights }\end{array}$ \\
\hline $\mathrm{C}_{11}$ & {$[1,1]$} & {$[2.36$,} & {$[1.09,1.37]$} & 0.633438 \\
$\mathrm{C}_{12}$ & {$[0.32,0.42]$} & {$[1,1]$} & {$[2.71,3.51]$} & 0.267838 \\
$\mathrm{C}_{13}$ & {$[0.76,0.93]$} & {$[0.30$,} & {$[1,1]$} & 0.098724 \\
\hline
\end{tabular}

(b)

\begin{tabular}{lccc}
\hline Social & $\mathrm{C}_{21}$ & $\mathrm{C}_{22}$ & Obtained weights \\
\hline $\mathrm{C}_{21}$ & {$[1,1]$} & {$[2.7,3.1]$} & 0.754717 \\
$\mathrm{C}_{22}$ & {$[0.32,0.47]$} & {$[1,1]$} & 0.245283 \\
\hline
\end{tabular}

(c)

\begin{tabular}{lccc}
\hline Economic & $\mathrm{C}_{31}$ & $\mathrm{C}_{32}$ & Obtained weights \\
\hline $\mathrm{C}_{31}$ & {$[1,1]$} & {$[3.68,4.73]$} & 0.821693 \\
$\mathrm{C}_{32}$ & {$[0.22,0.3]$} & {$[1,1]$} & 0.178307 \\
\hline
\end{tabular}

"C" with a value of 0.198146 , alternative "A" with a value of 0.090549 , alternative " $D$ " with a value of 0.070878 , and alternative "B" with a value of 0.036346 are in next order, respectively.

\section{Comparison with Other Existing Methods}

In addition, the fuzzy AHP methods in the literature are compared [30, 31] as shown in Table 21. There are significant differences in their hypothetical forms. The comparison includes positives and negative points of each method. Main positives of proposed method were assigned at the bottom of Table 21 and were denoted with bold font. For evaluation of proposed method, we applied Chang's method [32] in order to assess the aluminum waste management systems (see Table 22).

\section{Discussion}

As was previously noted, the secondary aluminum production increases quickly due to environmental issues and continuous growing of use demands. In this case, over 200 kilograms of aluminum black dross as waste is produced for each ton of secondary aluminum black dross is either duplicate recovered as by-products or landfilled. However, releasing this quantity in environment can produce considerable consequences from the air, the water, and the soil pollution point of view. Recovery, recycle, and disposal of aluminum wastes including aluminum dross and aluminum scrap are a global issue in terms of environmental, social, 
TABLE 13: The interval approximation purposed choices referring to GWP subcriteria.

\begin{tabular}{lcccccc}
\hline GWP & A & B & C & D & E & Obtained weights \\
\hline A & {$[1,1]$} & {$[3.02,4.06]$} & {$[0.33,0.4]$} & {$[2.5,3.5]$} & {$[0.15,0.17]$} & 0.090862 \\
B & {$[0.28,0.31]$} & {$[1,1]$} & {$[0.13,0.14]$} & {$[0.3,0.5]$} & {$[0.14,0.14]$} & 0.026054 \\
C & {$[1.96,2.96]$} & {$[7,7.5]$} & {$[1,1]$} & {$[4.5,5.5]$} & {$[0.23,0.27]$} & 0.195402 \\
D & {$[0.3,0.5]$} & {$[2.5,3.5]$} & {$[0.18,0.21]$} & {$[1,1]$} & {$[0.13,0.14]$} & 0.036345 \\
E & {$[5.7,6.76]$} & {$[7,7.5]$} & {$[3.68,4.72]$} & {$[6.8,7.5]$} & {$[1,1]$} & 0.651339 \\
\hline
\end{tabular}

TABLE 14: The interval approximation choices referring to ETP subcriteria.

\begin{tabular}{lcccccc}
\hline ETP & A & B & C & D & E & Obtained weights \\
\hline A & {$[1,1]$} & {$[2.5,3.5]$} & {$[0.22,0.21]$} & {$[1,1.5]$} & {$[0.18,0.22]$} & 0.041578 \\
B & {$[0.42,0.61]$} & {$[1,1]$} & {$[0.13,0.15]$} & {$[0.42,0.61]$} & {$[0.14,0.14]$} & 0.024023 \\
C & {$[3.68,4.72]$} & {$[7,7.5]$} & {$[1,1]$} & {$[6.5,7.5]$} & {$[0.23,0.27]$} & 0.180174 \\
D & {$[0.83,1]$} & {$[1.8,2.6]$} & {$[0.15,0.18]$} & {$[1,1]$} & {$[0.13,0.14]$} & 0.027719 \\
E & {$[3.5,4.5]$} & {$[6.8,7.5]$} & {$[3.68,4.72]$} & {$[6.8,7.5]$} & {$[1,1]$} & 0.726506 \\
\hline
\end{tabular}

TABLE 15: The interval approximation choices referring to LU subcriteria.

\begin{tabular}{lcccccc}
\hline LU & A & B & C & D & E & Obtained weights \\
\hline A & {$[1,1]$} & {$[5.74,6.67]$} & {$[0.83,1]$} & {$[3.02,4.06]$} & {$[0.25,0.38]$} & 0.173079 \\
B & {$[0.17,0.2]$} & {$[1,1]$} & {$[0.13,0.15]$} & {$[1,0.87]$} & {$[0.13,0.15]$} & 0.030116 \\
C & {$[1,1.5]$} & {$[7,7.5]$} & {$[1,1]$} & {$[4.5,5.5]$} & {$[0.5,0.6]$} & 0.223084 \\
D & {$[0.25,0.38]$} & {$[1,1.5]$} & {$[0.18,0.23]$} & {$[1,1]$} & {$[0.13,0.15]$} & 0.042567 \\
E & {$[3,4]$} & {$[7,7.5]$} & {$[1.8,2.6]$} & {$[7,7.5]$} & {$[1,1]$} & 0.531153 \\
\hline
\end{tabular}

TABLE 16: The interval approximation choices referring to H\&S subcriteria.

\begin{tabular}{lcccccc}
\hline H\&S & A & B & C & D & E & Obtained weights \\
\hline A & {$[1,1]$} & {$[0.21,0.25]$} & {$[0.27,0.34]$} & {$[0.13,0.14]$} & {$[0.13,0.15]$} & 0.037196 \\
B & {$[3.68,4.72]$} & {$[1,1]$} & {$[0.83,1]$} & {$[0.18,0.23]$} & {$[0.42,0.61]$} & 0.109401 \\
C & {$[3.68,4.72]$} & {$[1,1.5]$} & {$[1,1]$} & {$[0.13,0.14]$} & {$[0.83,1]$} & 0.164101 \\
D & {$[7,7.5]$} & {$[4.5,5.5]$} & {$[2.5,3.5]$} & {$[1,1]$} & {$[1.3,1.97]$} & 0.492303 \\
E & {$[6.8,7.5]$} & {$[1.8,2.6]$} & {$[1,1.5]$} & {$[0.62,0.69]$} & {$[1,1]$} & 0.197 \\
\hline
\end{tabular}

TABLE 17: The interval approximation choices referring to the regulation subcriteria.

\begin{tabular}{lcccccc}
\hline Regulation & $\mathrm{A}$ & $\mathrm{B}$ & $\mathrm{C}$ & $\mathrm{D}$ & $\mathrm{E}$ & Obtained weights \\
\hline $\mathrm{A}$ & {$[1,1]$} & {$[4.5,5.5]$} & {$[0.83,1]$} & {$[2.5,35]$} & {$[0.3,0.5]$} & 0.247475 \\
$\mathrm{~B}$ & {$[0.18,0.23]$} & {$[1,1]$} & {$[0.13,0.14]$} & {$[1,1]$} & {$[0.13,0.14]$} & 0.045455 \\
$\mathrm{C}$ & {$[0.92,1.3]$} & {$[7,7.5]$} & {$[1,1]$} & {$[4.5,5.5]$} & {$[1,1]$} & 0.318182 \\
$\mathrm{D}$ & {$[0.3,0.25]$} & {$[1,1]$} & {$[0.18,0.23]$} & {$[1,1]$} & {$[0.13,0.14]$} & 0.070707 \\
E & {$[2.5,3.5]$} & {$[7,7.5]$} & {$[1,1]$} & {$[7,7.5]$} & {$[1,1]$} & 0.318182 \\
\hline
\end{tabular}

TABLE 18: The interval approximation choices referring to turnover subcriteria.

\begin{tabular}{lcccccc}
\hline Turnover & $\mathrm{A}$ & $\mathrm{B}$ & $\mathrm{C}$ & $\mathrm{D}$ & $\mathrm{E}$ & Obtained weights \\
\hline $\mathrm{A}$ & {$[1,1]$} & {$[5.08,6.09]$} & {$[0.83,1]$} & {$[2.5,3.5]$} & {$[0.15,0.17]$} & 0.224165 \\
$\mathrm{~B}$ & {$[0.32,0.42]$} & {$[1,1]$} & {$[0.13,0.14]$} & {$[0.92,1]$} & {$[0.13,0.14]$} & 0.044833 \\
$\mathrm{C}$ & {$[1,1.5]$} & {$[6.81,7.5]$} & {$[1,1]$} & {$[5.74,6.76]$} & {$[1,1]$} & 0.336247 \\
$\mathrm{D}$ & {$[0.30,0.38]$} & {$[0.92,1]$} & {$[0.15,0.17]$} & {$[1,1]$} & {$[0.13,0.14]$} & 0.058508 \\
$\mathrm{E}$ & {$[4.43,5.44]$} & {$[7,7.5]$} & {$[1,1]$} & {$[7,7.5]$} & {$[1,1]$} & 0.336247 \\
\hline
\end{tabular}


TABLE 19: The interval approximation options concerning gain subcriteria.

\begin{tabular}{lcccccc}
\hline Gain & $\mathrm{A}$ & $\mathrm{B}$ & $\mathrm{C}$ & $\mathrm{D}$ & $\mathrm{E}$ & Obtained weights \\
\hline $\mathrm{A}$ & {$[1,1]$} & {$[1.22,1.81]$} & {$[0.59,0.77]$} & {$[1.82,2.43]$} & {$[3.68,4.72]$} & 0.322223 \\
B & {$[0.60,0.95]$} & {$[1,1]$} & {$[0.028,0.169]$} & {$[1.81,2.61]$} & {$[6.81,7.5]$} & 0.305145 \\
C & {$[0.18,0.23]$} & {$[0.54,0.67]$} & {$[1,1]$} & {$[0.25,0.38]$} & {$[1,1]$} & 0.159262 \\
D & {$[1,1.5]$} & {$[0.3,0.5]$} & {$[0.30,0.38]$} & {$[1,1]$} & {$[6.5,7.5]$} & 0.168588 \\
E & {$[0.21,0.28]$} & {$[0.13,0.15]$} & {$[2.36,2.96]$} & {$[0.14,0.16]$} & {$[1,1]$} & 0.044782 \\
\hline
\end{tabular}

TABLE 20: The results of ranking aluminum waste management system options.

\begin{tabular}{lcc}
\hline Alternatives & Final obtained weights & Rank of alternatives \\
\hline A & 0.090549 & 3 \\
B & 0.036346 & 5 \\
C & 0.198146 & 2 \\
D & 0.070878 & 4 \\
E & 0.594161 & 1 \\
Ranking order & E $>$ C $>$ A $>$ D > B \\
\hline
\end{tabular}

and economic aspects. The presented model for industrial waste management alternatives was implemented in the case of aluminum waste systems in the industrial city of Arak. The application of LCA to the aluminum waste management system will be a feasible way. However, LCA works have commonly an intrinsic ambiguity due to different categories. In addition, no single solution is available as each industry in each country has different characteristics in terms of geographical and environmental as well as social and economic aspects. Several management decisions are required to provide efficient aluminum waste management systems. The objective of this research is to propose an integrated FAHP in the aluminum waste management system. The model for the aluminum waste management system, which integrates social, economic, and environmental aspects, is the MCDM problem. This study has presented a model, based on the fuzzy concept, to compare aluminum waste management systems. It may mainly evaluate and contains interdependence relationship amongst the criteria under ambiguity. The results of the research represent that the method is easy in computation and setting priorities. Hence, it is mainly appropriate for solving MCDM problems. At this research we apply environmental, social, and economic criteria for evaluation and support decision-making within the aluminum industry as the MCDM problem. On the other hand, the fuzzy AHP can be utilized not only as a method to handle the interdependence within a collection of criteria, but also as a method of generating more noteworthy data for decision-making. The model also has disadvantages. For example, FAHP model uses the aggregated categories' data that several subcategories are evaluated under the same main category. This will increase the uncertainty in FAHP based on LCA results that can be solved by using more specific life cycle data for several steps of aluminum waste. It is significant to regard that the weights of subcriteria obtained from expert judgment are also subject to uncertainties. With changing weights, a fuzzy MCDM decision-making method might give different results for the ranking of aluminum waste management alternatives. Seven subcriteria are considered from a group of three main criteria, namely, environmental, social, and economic. First, decision-makers evaluated each waste management alternative for selected criteria and subcriteria. Second, we obtained these evaluation results taking into account the weight of the criteria and subcriteria. Also, we transformed collected data into the fuzzy intuitionistic version. Finally, we applied a real MCDM problem for the proposed decision-making method. The model aims to rank waste management alternatives. Relevant to the outcomes of expert judgment, the most important environmental subcriteria are determined as global warming, human toxicity, and land use. The most influential social indicator is indicated as health and safety at work and regulation, and the most influential economic subcriteria are determined as turnover and gain.

The results showed that alternative $\mathrm{E}$ has the highest ranking compared to other alternatives. Also, alternative $\mathrm{C}$ and alternative A are ranked third and fourth, respectively. Apart from these three, other alternatives of aluminum waste management system, as alternative $\mathrm{D}$ and alternative $B$, ranked fourth and fifth, respectively. Each alternative presents a solution for the aluminum waste management system with a certain degree of trade-off between benefit and its consequences related to environmental, social, and economic issues. For example, the choice of alternative $\mathrm{C}$ could be increased by the increasing amount of aluminum scraps, related to the primary aluminum production process. Also alternative $\mathrm{D}$ represents the export of aluminum waste to other places in the form of black dross or aluminum dross with less metallurgic aluminum. From the application perspective, this research will provide a valuable insight for managers to attempt to improve the environmental, social, and economic condition all together at the same time.

\section{Conclusions}

Nowadays, thanks to increased awareness and important environmental pressures from various stakeholders, environmental issues in daily activities are considered by industries. However, so far, little attention has been given to environmental aspects of processing output of aluminum dross and aluminum scrap as aluminum waste. All the information collected was related to LCA result, written documents, and findings from interviews. For the proposed integrated fuzzy AHP model, the five alternatives are investigated. In this study we applied the NWIA of FN to transform each fuzzy 
TABLE 21: The comparison of various FAHP models [30, 31].

\begin{tabular}{|c|c|c|}
\hline Sources & Basic specifications & Positives $(\mathrm{P}) /$ negatives $(\mathrm{N})$ \\
\hline \multirow{4}{*}[15]{} & $\begin{array}{l}\text { Direct extension of Saaty's AHP model with triangular } \\
\text { fuzzy numbers }\end{array}$ & $\begin{array}{l}\text { (P) The judgments of multiple experts may be modeled } \\
\text { in the reciprocal matrix }\end{array}$ \\
\hline & \multirow{3}{*}{$\begin{array}{l}\text { Lootsma's logarithmic least square model is used to } \\
\text { derive fuzzy weights and fuzzy performance scores }\end{array}$} & $\begin{array}{l}\text { (N) Evermore there is no solution to the linear } \\
\text { equations }\end{array}$ \\
\hline & & $\begin{array}{l}\text { (N) The calculational demand is great, even for a low } \\
\text { problem }\end{array}$ \\
\hline & & (N) It permits only triangular FN to be applied \\
\hline \multirow{3}{*}[16]{} & $\begin{array}{l}\text { Direct extension of Saaty's AHP model with trapezoidal } \\
\text { fuzzy numbers }\end{array}$ & (P) It is simple to extend to the fuzzy term \\
\hline & \multirow{2}{*}{$\begin{array}{l}\text { Uses the geometric mean model to derive fuzzy weights } \\
\text { and performance scores }\end{array}$} & $\begin{array}{l}\text { (P) It guarantees an alone solution to the reciprocal } \\
\text { comparison matrix }\end{array}$ \\
\hline & & (N) The calculational demand is great \\
\hline \multirow[b]{2}{*}{ [33] } & Modifies van Laarhoven and Pedrycz's model & (P) The judgments of multiple experts may be modeled \\
\hline & $\begin{array}{l}\text { Shows a more robust method to the normalization of } \\
\text { the local priorities }\end{array}$ & (N) The calculational demand is great \\
\hline \multirow{3}{*}{ [32] } & Synthetical degree values & (P) The calculational demand is partly low \\
\hline & Layer simple sequencing & $\begin{array}{l}\text { (P) It follows the steps of crisp AHP; it does not involve } \\
\text { additional process }\end{array}$ \\
\hline & Composite total sequencing & (N) It permits only triangular FN to be applied \\
\hline \multirow{3}{*}[32]{} & Creates fuzzy standards & (P) The calculational demand is not great \\
\hline & $\begin{array}{l}\text { Illustrates performance numerals by membership } \\
\text { functions }\end{array}$ & $\begin{array}{l}\text { (N) Entropy is applied when probability distribution is } \\
\text { known. The model is based on both probability and } \\
\text { possibility measures }\end{array}$ \\
\hline & Uses entropy concepts to calculate aggregate weights & \\
\hline \multirow{3}{*}{ Proposed method } & \multirow{2}{*}{ Uses interval approximation to defuzzification } & (P) It permits all FN to be applied \\
\hline & & (P) It retains uncertainty of fuzzy number in itself \\
\hline & Uses goal programming method to obtain weights & (P) It is done, mainly, with a software such as Lingo \\
\hline
\end{tabular}

TABLE 22: The comparison of results of proposed method and Chang's fuzzy AHP method.

\begin{tabular}{lcccc}
\hline Alternatives & Weights (proposed) & Rank of alternatives & Weights (Chang's method) & Rank of alternatives \\
\hline A & 0.090549 & 3 & 0.094855 & 3 \\
B & 0.036346 & 5 & 0.006343 & 5 \\
C & 0.198146 & 2 & 0.305851 & 2 \\
D & 0.070878 & 4 & 0.01511 & 4 \\
E & 0.5941 & 1 & 0.409039 \\
Ranking order (the proposed method) & E $>$ C $>$ A > D > B & E $>$ C $>$ A > D > B \\
Ranking order (Chang's method) & \multicolumn{5}{c}{} & \\
\hline
\end{tabular}

component of the pairwise matrix to its NWIA. Then, we applied the GP model for weighting and LINGO 11 to resolve. The results showed that alternative $\mathrm{E}$ and alternative $\mathrm{B}$ are assigned as the best and the worst preferred choice with weights of 0.594161 and 0.036346 , respectively. In alternative $\mathrm{E}$, aluminum batch includes primary aluminum ingot $99.5-$ $20 \%$ and secondary aluminum (aluminum scrap 98-80\%), beneficiation activities related to input aluminum scrap such as washing, separating, and sorting, duplicate aluminum dross recycling in plant, and landfill, while in alternative B aluminum batch includes primary aluminum ingot $99.5-20 \%$ and secondary aluminum (aluminum scrap 96-80\%), remelting without beneficiation activities, exporting remaining aluminum dross to other places, and duplicate recycling and release in the environment.

According to above-mentioned consideration, uncertainty in the LCA results and limitations of the current method should be taken into account by decision-makers. First of all, the methodology may be utilized for similar problems where multiple criteria are present. This research will supply a valuable insight for the directors to try to improve the environmental, social, and economic condition all together simultaneously. In future research, current fuzzy approach can be developed and applied for different MCDM problems in industry where conflicting criteria exist. 


\section{Conflict of Interests}

The authors declare that there is no conflict of interests regarding the publication of this paper.

\section{References}

[1] J.-P. Hong, J. Wang, H.-Y. Chen, B.-D. Sun, J.-J. Li, and C. Chen, "Process of aluminum dross recycling and life cycle assessment for Al-Si alloys and brown fused alumina," Transactions of Nonferrous Metals Society of China, vol. 20, no. 11, pp. 2155-2161, 2010.

[2] S. Khamis, M. Lajis, and R. Albert, "A sustainable direct recycling of aluminum chip (AA6061) in hot press forging employing response surface methodology," Procedia CIRP, vol. 26, pp. 477-481, 2015.

[3] T. Norgate and S. Jahanshahi, "Reducing the greenhouse gas footprint of primary metal production: where should the focus be?” Minerals Engineering, vol. 24, no. 14, pp. 1563-1570, 2011.

[4] G. Liu, C. E. Bangs, and D. B. Müller, "Stock dynamics and emission pathways of the global aluminium cycle," Nature Climate Change, vol. 3, no. 4, pp. 338-342, 2013.

[5] G. Liu and D. B. Müller, "Addressing sustainability in the aluminum industry: a critical review of life cycle assessments," Journal of Cleaner Production, vol. 35, pp. 108-117, 2012.

[6] M. C. Shinzato and R. Hypolito, "Solid waste from aluminum recycling process: characterization and reuse of its economically valuable constituents," Waste Management, vol. 25, no. 1, pp. 3746, 2005.

[7] H. I. Gomes, W. M. Mayes, M. Rogerson, D. I. Stewart, and I. T. Burke, "Alkaline residues and the environment: a review of impacts, management practices and opportunities," Journal of Cleaner Production, 2015.

[8] P. H. Brunner and H. Rechberger, "Waste to energy-key element for sustainable waste management," Waste Management, vol. 37, pp. 3-12, 2015.

[9] A. Abdulkadir, A. Ajayi, and M. I. Hassan, "Evaluating the chemical composition and the molar heat capacities of a white aluminum dross," Energy Procedia, vol. 75, pp. 2099-2105, 2015.

[10] S. O. Adeosun, M. A. Usman, W. A. Ayoola, and I. O. Sekunowo, "Evaluation of the mechanical properties of polypropylenealuminum-dross composite," ISRN Polymer Science, vol. 2012, Article ID 282515, 6 pages, 2012.

[11] T. W. Unger and M. Beckmann, "Salt slag processing for recycling," in Proceedings of the Sessions, Light Metals, TMS Annual Meeting (TMS '92), pp. 1159-1162, San Diego, Calif, USA, 1992.

[12] A. Weckenmann and A. Schwan, "Environmental Life Cycle Assessment with support of fuzzy-sets," The International Journal of Life Cycle Assessment, vol. 6, no. 1, pp. 13-18, 2001.

[13] L. P. Güereca, N. Agell, S. Gassó, and J. M. Baldasano, "Fuzzy approach to life cycle impact assessment," The International Journal of Life Cycle Assessment, vol. 12, no. 7, pp. 488-496, 2007.

[14] J. Seppälä, "On the meaning of fuzzy approach and normalisation in life cycle impact assessment," The International Journal of Life Cycle Assessment, vol. 12, no. 7, pp. 464-469, 2007.

[15] P. J. M. Van Laarhoven and W. Pedrycz, "A fuzzy extension of Saaty's priority theory," Fuzzy Sets and Systems, vol. 11, no. 1-3, pp. 229-241, 1983.
[16] R. C. Buckley, "Distinguishing the effects of area and habitat type on island plant species richness by separating floristic elements and substrate types and controlling for island isolation," Journal of Biogeography, vol. 12, no. 6, pp. 527-535, 1985.

[17] M. Weck, F. Klocke, H. Schell, and E. Rüenauver, "Evaluating alternative production cycles using the extended fuzzy AHP method," European Journal of Operational Research, vol. 100, no. 2, pp. 351-366, 1997.

[18] M. R. Abdi, "Fuzzy multi-criteria decision model for evaluating reconfigurable machines," International Journal of Production Economics, vol. 117, no. 1, pp. 1-15, 2009.

[19] H. K. Chan, X. Wang, G. R. T. White, and N. Yip, "An extended fuzzy-AHP approach for the evaluation of green product designs," IEEE Transactions on Engineering Management, vol. 60, no. 2, pp. 327-339, 2013.

[20] L. Wang, H. Zhang, and Y.-R. Zeng, "Fuzzy analytic hierarchy process (FAHP) and balanced scorecard approach for evaluating performance of Third-Party Logistics (TPL) enterprises in Chinese context," African Journal of Business Management, vol. 6, no. 2, pp. 521-529, 2012.

[21] G. Zheng, Y. Jing, H. Huang, and Y. Gao, "Applying LCA and fuzzy AHP to evaluate building energy conservation," Civil Engineering and Environmental Systems, vol. 28, no. 2, pp. 123141, 2011.

[22] C.-Y. Lin, A. H. I. Lee, and H.-Y. Kang, "An integrated new product development framework - an application on green and low-carbon products," International Journal of Systems Science, vol. 46, no. 4, pp. 733-753, 2015.

[23] L. A. Zadeh, "Fuzzy sets," Information and Control, vol. 8, no. 3, pp. 338-353, 1965.

[24] S.-J. C. C.-L. Hwang and F. P. Hwang, Fuzzy Multiple Attribute Decision Making, Springer, 1992.

[25] J. Ramík and P. Korviny, "Inconsistency of pair-wise comparison matrix with fuzzy elements based on geometric mean," Fuzzy Sets and Systems, vol. 161, no. 11, pp. 1604-1613, 2010.

[26] M. Izadikhah, "Deriving weights of criteria from inconsistent fuzzy comparison matrices by using the nearest weighted interval approximation," Advances in Operations Research, vol. 2012, Article ID 574710, 17 pages, 2012.

[27] G.-H. Tzeng and J.-J. Huang, Fuzzy Multiple Objective Decision Making, CRC Press, 2013.

[28] T. L. Saaty, "What is the analytic hierarchy process?" in Mathematical Models for Decision Support, vol. 48 of NATO ASI Series, pp. 109-121, Springer, Berlin, Germany, 1988.

[29] F. T. S. Chan and N. Kumar, "Global supplier development considering risk factors using fuzzy extended AHP-based approach," Omega, vol. 35, no. 4, pp. 417-431, 2007.

[30] Z. Ayağ and R. G. Özdemir, "A fuzzy AHP approach to evaluating machine tool alternatives," Journal of Intelligent Manufacturing, vol. 17, no. 2, pp. 179-190, 2006.

[31] G. Büyüközkan, C. Kahraman, and D. Ruan, "A fuzzy multicriteria decision approach for software development strategy selection," International Journal of General Systems, vol. 33, no. 2-3, pp. 259-280, 2004.

[32] D.-Y. Chang, "Applications of the extent analysis method on fuzzy AHP," European Journal of Operational Research, vol. 95, no. 3, pp. 649-655, 1996.

[33] C. G. Boender, J. G. De Graan, and F. A. Lootsma, "Multicriteria decision analysis with fuzzy pairwise comparisons," Fuzzy Sets and Systems, vol. 29, no. 2, pp. 133-143, 1989. 

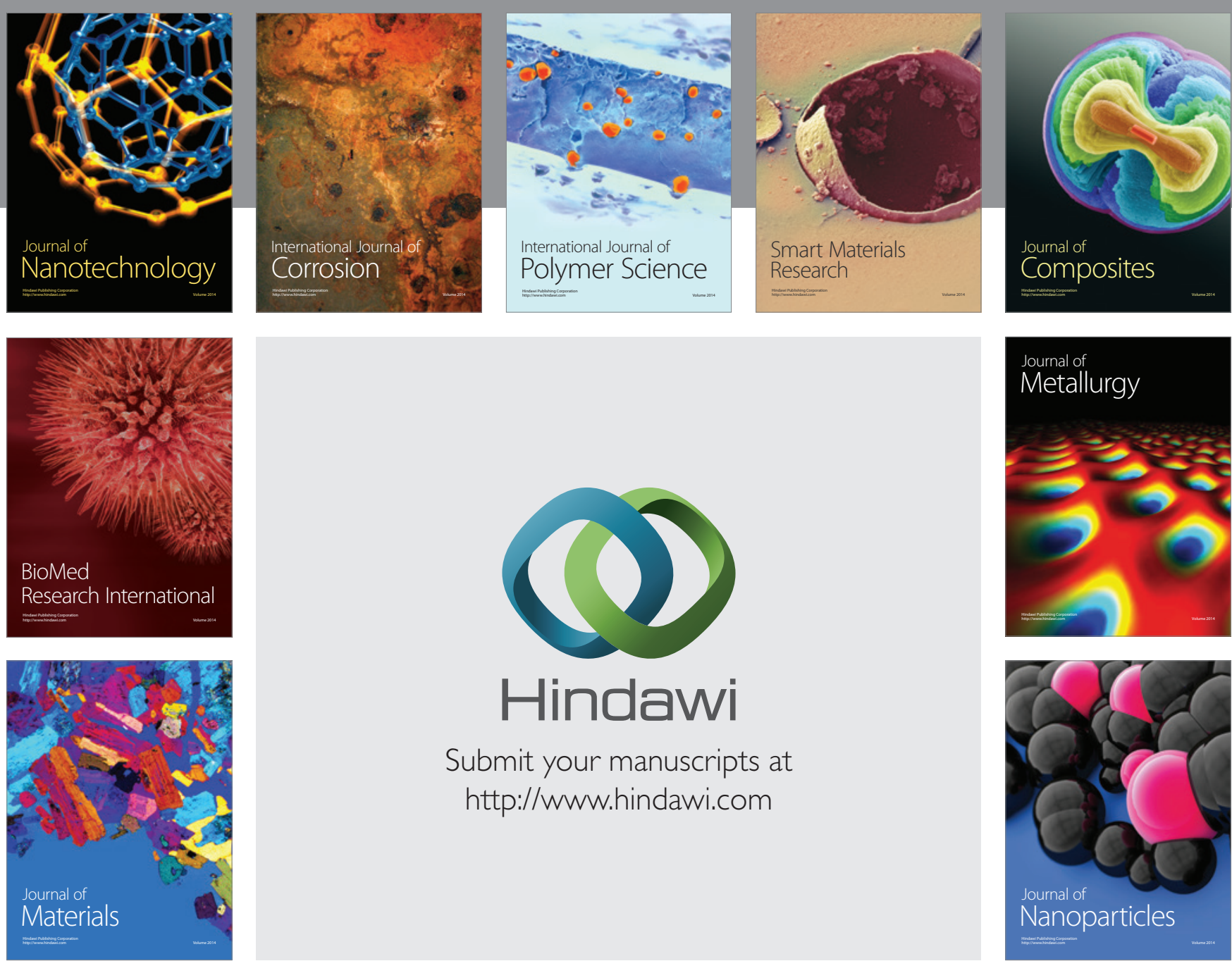

\section{Hindawi}

Submit your manuscripts at

http://www.hindawi.com

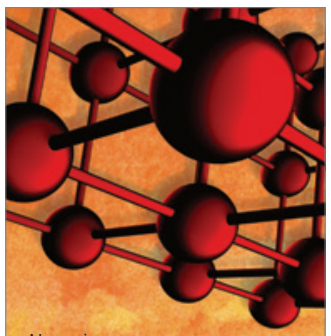

Materials Science and Engineering
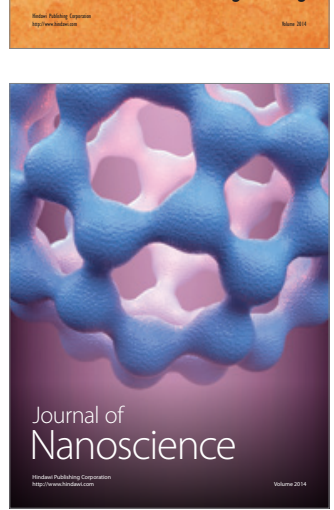
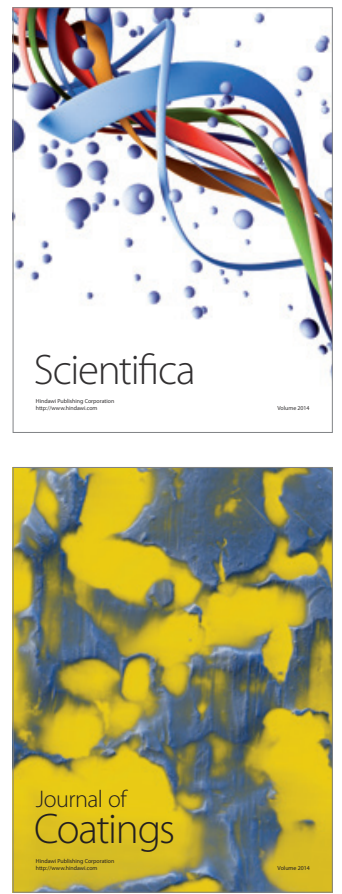
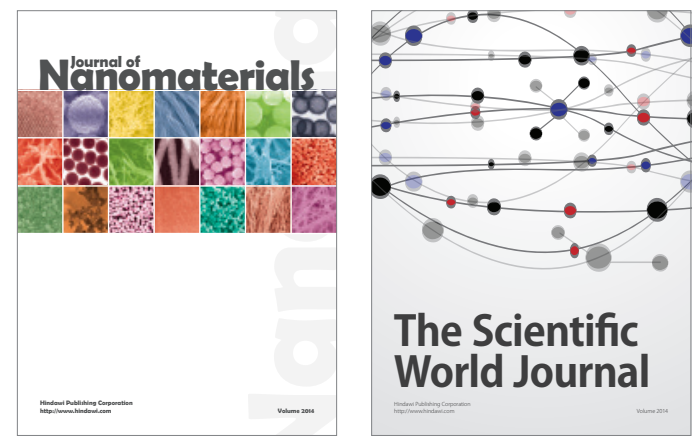

The Scientific World Journal
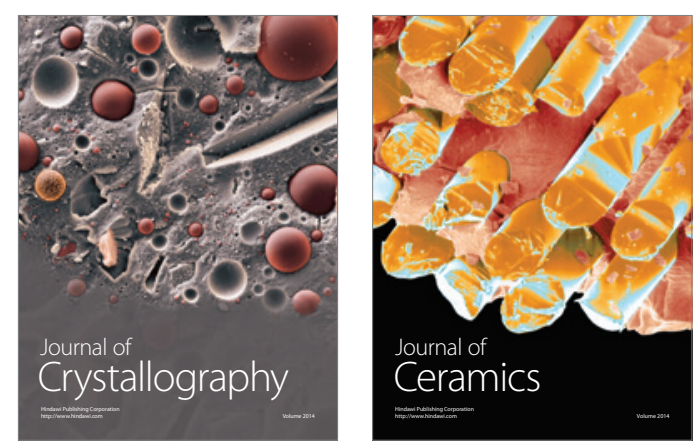
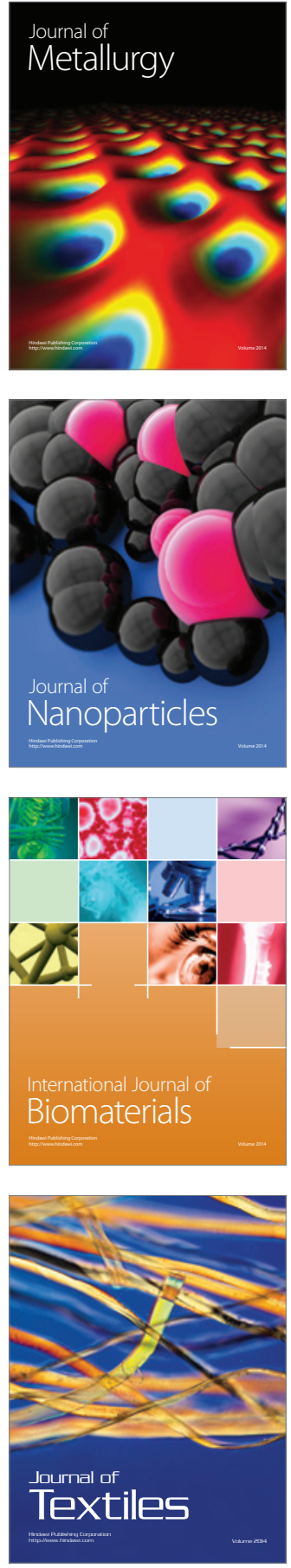